\title{
Strawberry Harvesting Robot for Bench-type Cultivation
}

\author{
Kil-Su Han ${ }^{1}$, Si-Chan Kim², Young Bum Lee ${ }^{1}$, Sang Chul Kim¹, \\ Dong Hyuk $\mathrm{Im}^{1}$, Hong Ki Choi ${ }^{1}$, Heon Hwang ${ }^{2}$ \\ ${ }^{1}$ National Academy of Agricultural Science, RDA, Suwon, Korea, ${ }^{2}$ Department of Bio-Mechatronic \\ Engineering, Sungkyunkwan University, Suwon, Korea
}

Received: February $14^{\text {th }}, 2011$; Revised: December $26^{\text {th }}, 2011$; Accepted: February $28^{\text {th }}, 2012$

\section{Abstract}

Purpose: An autonomous robot was developed for harvesting strawberries cultivated in bench-type systems. Methods: The harvest robot consisted of four main components: an autonomous vehicle, a manipulator with four degrees of freedom (DOF), an end effector with two DOFs, and a color computer vision system. Strawberry detection was performed based on 3D image and distance information obtained from a stereo CCD color camera and a laser device, respectively. Results: In this work, a Cartesian type manipulator system was designed, including an intermediate revolute axis and a double driven arm-based joint axis, so that it could generate collision-free motions during harvesting. A DC servomotor-driven end-effector, consisting of a gripper and a cutter, was designed for gripping and cutting the strawberry stem without damaging the strawberry itself. Real-time position tracking algorithms were developed to detect, recognize, trace, and approach strawberries under natural light conditions. Conclusion: The developed robot system could harvest a strawberry within 7 seconds without damage.

Keywords: End effector, Harvesting robot, Manipulator, Stereo vision, Strawberries, Visual feedback

\section{Introduction}

According to the Korean Food and Agriculture Organization (KOFAO) in 2007, the cultivating area for strawberries was 7,600 ha which was ranked 7 in the world. Production amount was 203,227 MT, ranking it in 4th place internationally, and the number of cultivating farmhouses is over 16,000. Strawberry species, Sul-hyang and Mae-hyang had a portion of $62.7 \%$ of total production with representing others. Labor required per 10ha was 613.9 hours in a case of semi-forcing with 250.3 harvesting labor hours. Labor required per 10 ha was 590.6 hours in a case of forcing cultivation with 208.7 harvesting labor hours. (RDA , 2008)

There has been a great demand in Korea for the mechanization and automation of strawberry cultivation,

\footnotetext{
*Corresponding author: Kil-Su Han

Tel: +82-31-290-1870; Fax: +82-31-290-1860

E-mail: han3188@korea.kr
}

especially in selective harvesting of ripened strawberries. Also, visual treatment technology with supporting visual information to worker to guarantee value-added high quality fresh produce was exercised during cultivation.

In the case of greenhouse cultivation, the lighting system was composed of a combination of natural and artificial lights. In automating the harvest process using computer vision to select the ripened strawberries, visual images acquired under this lighting environment usually had problems with distortion caused by the variation of light reflection and shadow effects according to the direction of the light.

The harvest robot using a suction type end effector was developed for the strawberries cultivated in the soil ground by Kondo(2000). Fruit detachment and on-line classification of strawberry ripeness was proposed by Guo Feng et al(2008).

In this research, a strawberry harvesting robot system was developed using visual servo technology. A endoscope 
type end-effector was also developed. A computer vision system was utilized as a visual servo to detect and trace ripened strawberries selectively.

\section{Materials and Methods}

\section{Materials and environment}

The strawberry species used in this research was 'Jang-hee' and was cultivated in a bench type environment (Figure 1). Strawberries were harvested via gripping and cutting the stem rather than directly grasping strawberries to protect the quality of the strawberry itself. The specifications of the bench bed used for the harvesting test are presented in Table 1 and were utilized as a major design criterion to develop a robot system.

\section{Robot design}

\section{Workspace}

A custom harvest workspace was specified as 70 80 $\mathrm{cm}$ high from the ground and $80 \sim 90 \mathrm{~cm}$ wide. The manipulator actuating range was designed to have a 30

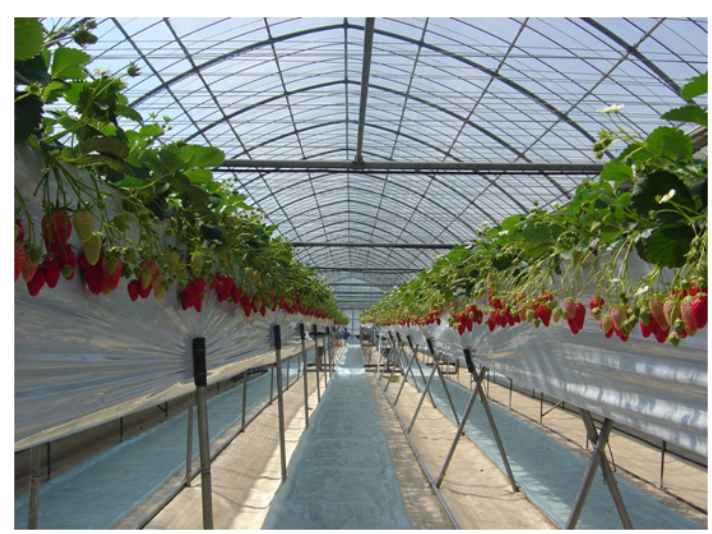

$\mathrm{cm}$ stroke along the $\mathrm{Z}$ axis (vertical direction), a $30 \mathrm{~cm}$ stroke along the $\mathrm{Y}$ axis (horizontal forward direction), and a $270^{\circ}$ rotation around the vertical axis.

\section{Payload}

The weight of a typical strawberry was normally under $30 \mathrm{~g}$, but the strawberries were very fragile towards mishandling because of their soft skin. In designing the robot payload, the weight of strawberry was ignored. A value of $4 \mathrm{kgf}$ was set considering the possible weight of an end-effector (Stem cutter $1.0 \mathrm{kgf}$, Gripper $1.0 \mathrm{kgf}$, Strawberry weight $0.01 \mathrm{kgf}$ with safety factor).

\section{Components of the robot system}

\section{Manipulator}

The robot manipulator was designed to have an additional revolute axis in addition to the Cartesian type link structure shown in Figure 2. Each joint axis was set so that the $\mathrm{X}$ axis was parallel to the line of cultivation, the $\mathrm{Y}$ axis corresponded to the vertical height, and the $\mathrm{Z}$ axis was in the approaching direction towards the strawberry plants. The rotating axis was additionally introduced to

\section{Z (Approach height)}

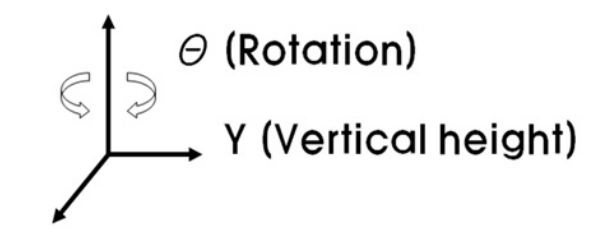

$X$ (Parallel to the line of cultivation)

Figure 1. Strawberries cultivated in the bench bed.

\section{Table 1. Specification of strawberry cultivating bench}

\begin{tabular}{|cc}
\hline Width $(\mathrm{cm})$ & 40 \\
\hline Height $(\mathrm{cm})$ & 100 \\
\hline $\begin{array}{c}\text { Bridge pipe } \\
\text { measurement }(\mathrm{mm})\end{array}$ & $\varnothing 25.4 \times 1.5 \mathrm{t}$ \\
\hline $\begin{array}{c}\text { Horizontal pipe } \\
\text { measurement }(\mathrm{mm})\end{array}$ & $\varnothing 25.4 \times 1.5 \mathrm{t}$ \\
\hline Bridge interval $(\mathrm{cm})$ & $80 \sim 90$ \\
\hline
\end{tabular}

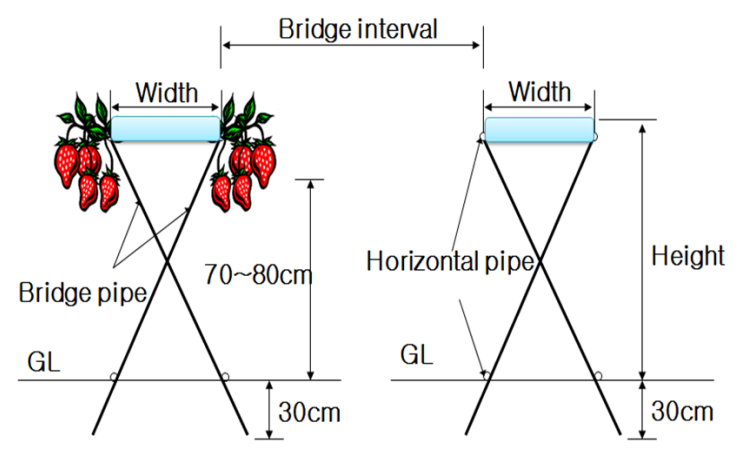




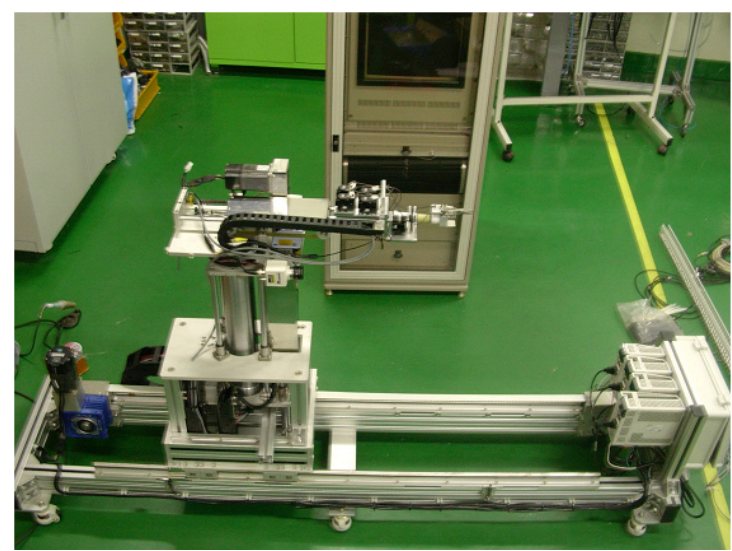

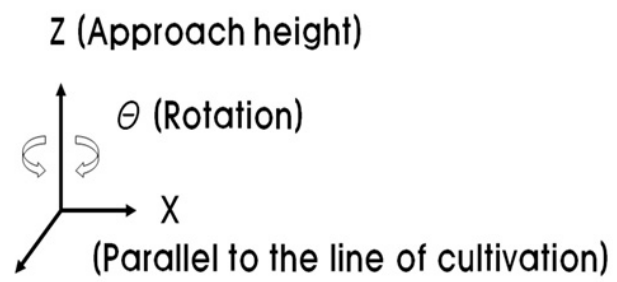

$Y$ (Vertical height)

Figure 2. Manipulator design of strawberry harvesting robot.

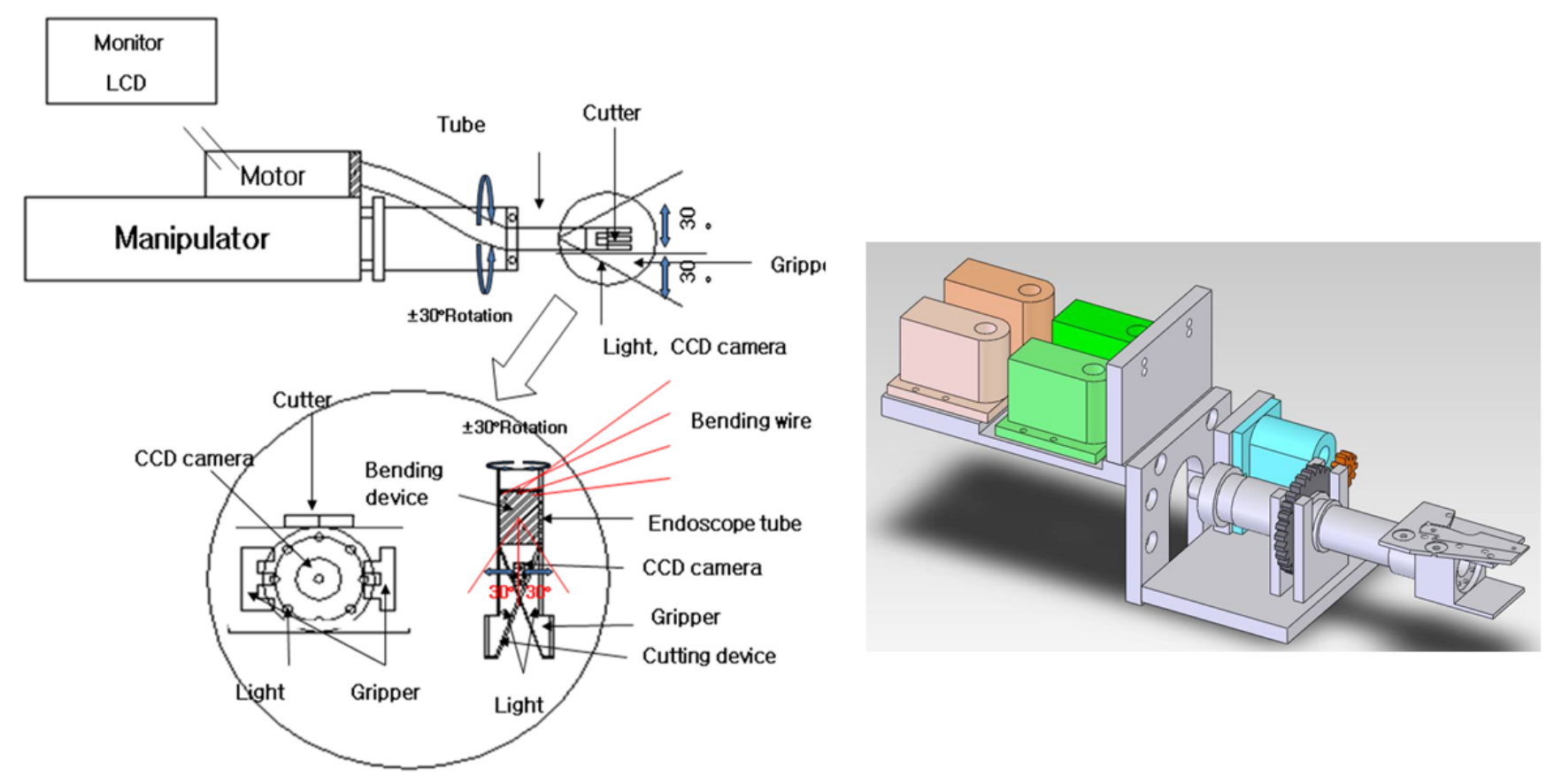

Figure 3. Structure and specification of the end-effector.

work for both planting sides. The movement range along each axis was $1,000 \mathrm{~mm}$ for the $\mathrm{X}$ axis, $700 \sim 1,000 \mathrm{~mm}$ for the $\mathrm{Y}$ axis, and $300 \mathrm{~mm}$ for the $\mathrm{Z}$ axis, and The rotating angle about the $\mathrm{Z}$ axis was $340^{\circ}$.

\section{End-effector}

To cut the stem of the strawberry in harvesting, the end-effector should be operated selectively without damaging other stems, leaves, or strawberries. As shown in Figure 3, the end-effector operation was performed with minimal spatial movement using an endoscope structure.

To compensate for the change of cutting location caused by the bending effect of an end-effector, a color camera was installed at the end. Cutting device and a gripper were also installed to hold stem. The cutting torque of the gripper was set to be $4 \sim 9 \mathrm{kgf} \cdot \mathrm{cm}$ so that it would have enough torque to compensate for torque loss to bend wires.

To set the appropriate angle (roll, pitch, yaw) for the end-effector, the typical strawberry stem inclination was investigated as shown in Figure 4 and in Table 2. Angles between strawberry stems and the vertical line were less than 15 degrees. The length of a stem to be cut from the top of the strawberry was maximum $15 \mathrm{~mm}$. The stroke for cutting should be more than $6 \mathrm{~mm}$ (sample 100 sets). 


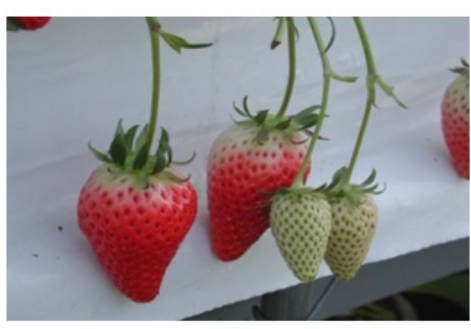

Left side $45^{\circ}$

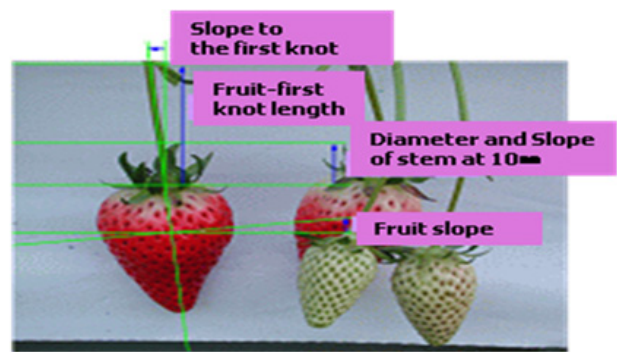

Front side

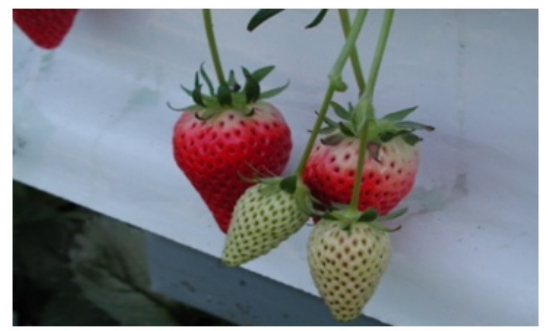

Right side $45^{\circ}$

Figure 4. Vertically inclined angles of strawberry stems

Table 2. Strawberry position and slope of stems

\begin{tabular}{lcccc} 
& Left & Front & Right & Minimum - Maximum \\
Slope at $10 \mathrm{~mm}$ & S0-L14 & L2-R10 & R5-R12 & L14-R12 \\
Diameter of stem at $10 \mathrm{~mm}$ & $3.3-5.1$ & $3.3-5.7$ & $3.0-5.4$ & $3.0-5.7$ \\
Slope to the first knot & S0-L12 & L12-R7 & S0-R11 & L12-R11 \\
Fruit slope & L10-R24 & S0-R21 & S0-R20 & L10-R24 \\
Fruit-first knot length $(\mathrm{mm})$ & $17-38$ & $15-38$ & $18-38$ & $15-38$ \\
\hline
\end{tabular}

$S$ : Straight direction

$\mathrm{L}$ : Left direction

$\mathrm{R}$ : Right direction

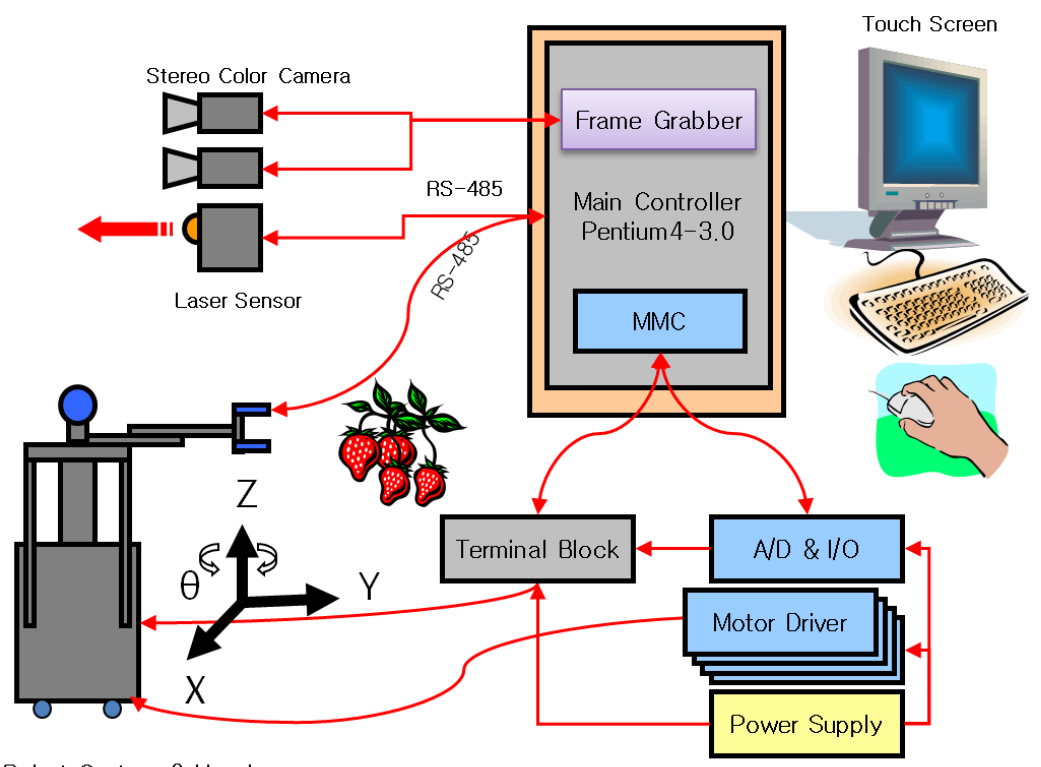

Robot System \& Hand

Figure 5. Block diagram of system control structure of strawberry harvesting robot system.

\section{System controller}

To selectively harvest ripened strawberries, the location information of the ripened strawberry was extracted using a laser range finder and color images. For real-time visual servo control of the robot end effector, two color CCD cameras were installed. Color stereo images were utilized to determine the ripeness level of the straw- berries. A laser range finder with an accuracy of \pm 0.45 $\mathrm{mm}$ was used to measure the distance between the end effector and the strawberries. An additional color CCD camera (Figure 3) was installed at the end of the end effector as a tool for visual servoing to guarantee the precise trace operation of an end effector. Figure 5 shows a block diagram of the system control structure for the 
strawberry harvesting robot system.

\section{Image processing}

\section{Object extraction}

RGB (red, green, and blue) images from camera was converted to HIS (Hue, Intensity, and Saturation) images using equation (1), (2), and (3). (Gonzalez R.C. and Woods R.E. USA)

$$
\begin{aligned}
& H=\cos ^{-1}\left[\frac{\frac{1}{2}(R-G)+(R-B)}{\sqrt{(R-G)^{2}+(R-B)(G-B)}}\right] \\
& S=1-\frac{3}{(R+G+B)}[\min (R, G, B)] \\
& I=\frac{1}{3}(R+G+B)
\end{aligned}
$$

For real-time processing, an area of interest was detected first by reducing the image resolution to $1 / 4$ of the original one. Median filtering with a $7 \times 7$ kernel was used to remove small salt and white noise and to reduce highlights while maintaining the boundary of the object. Then the area of interest was segmented from the background.

The color of a ripened strawberry was usually red while the color of an immature strawberry was light green. Leaves and stems had green color (Hue image between 300 to 60 degree, red range) and the background had low saturation. Considering the above characteristics, the bandwidth thresholding about color and saturation was performed, and logical operation was done using each thresholded image. Then the labeling process was performed.

Binary shape images of strawberries were modeled as circle, triangle, ellipse, or diamond caused by the partial ripeness of the surface. The centroid of the segment was computed and then the outside boundary was computed to form the rectangular area of the strawberry. The rectangular area was superimposed on the original resolution image to find the exact location of the strawberry.

From the area of the strawberry determined via superposition, a new center of gravity was obtained and used as the target.

A strawberry can be easily damaged if the end effector grips the strawberry directly. As shown in Figure 6, using

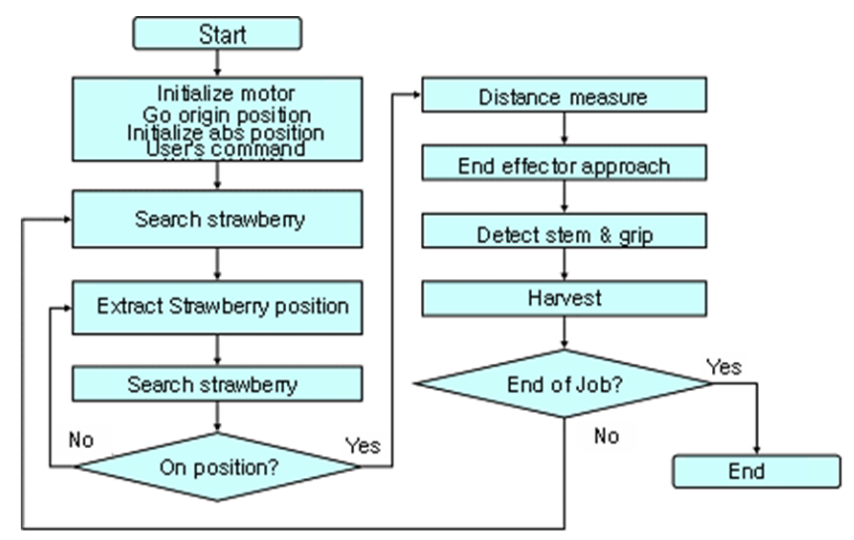

Figure 6. 3-Dimensional location tracing algorithm flow chart.

visual feedback, a strawberry was traced precisely.

\section{Robot performance}

The robot was repeatedly operated 100 times for each axis with 2 level speeds for check position errors, and a dial gauge was installed at the stop point to measure the accuracy and repeatability of joint movement. The speed was set to $300 \mathrm{~mm} / \mathrm{s}$ and $600 \mathrm{~mm} / \mathrm{s}$ for the $\mathrm{X}$ axis, 150 $\mathrm{mm} / \mathrm{s}$ and $300 \mathrm{~mm} / \mathrm{s}$ for the $\mathrm{Y}$ axis, $150 \mathrm{~mm} / \mathrm{s}$ and 270 $\mathrm{mm} / \mathrm{s}$ for the $Z$ axis, and $0.5 \pi \mathrm{rad} / \mathrm{s}$ and $\pi \mathrm{rad} / \mathrm{s}$ for the revolute axis. The movement range was $600 \mathrm{~mm}$ for the $\mathrm{X}$ axis, $300 \mathrm{~mm}$ for the $\mathrm{Y}$ axis, $270 \mathrm{~mm}$ for the $\mathrm{Z}$ axis, and $90^{\circ}$ for the revolute axis.

\section{Result and Discussion}

The robot manipulator was developed as shown in Figure 7. The specifications are presented in Table 3. The

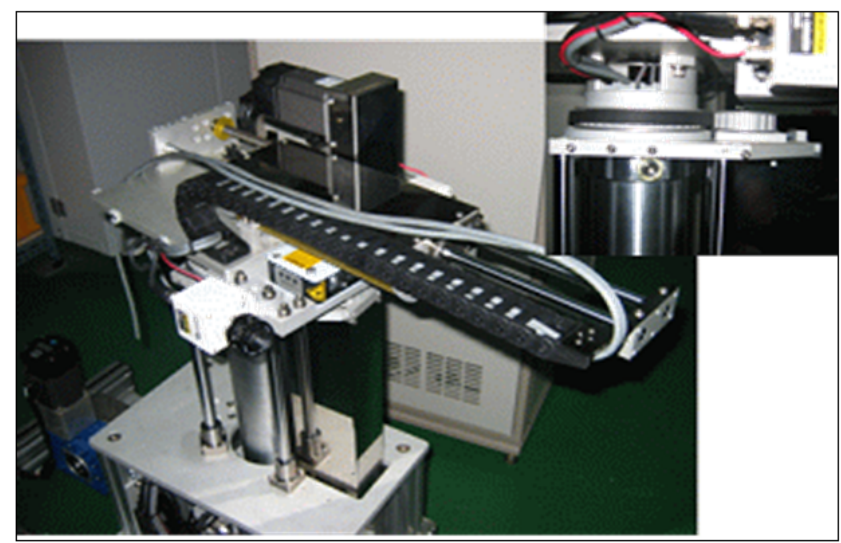

Figure 7. DOF (PRPP) robot arm with double driven joint axis along approaching direction. 


\begin{tabular}{|c|c|}
\hline Item & Measurement \\
\hline $\begin{array}{l}\text { Dimension } \\
\text { (Width } \times \text { length } \times \text { Height }: \mathrm{cm})\end{array}$ & $43 \times 35 \times 74$ \\
\hline Level of Freedom & Parallel 3 , Series 1 \\
\hline Distance $(\mathrm{cm})$ & $\begin{array}{l}X \text { axis } 100, Y \text { axis } 30, \\
Z \text { axis } 30 \text {, Rotation } 340 \text { degrees }\end{array}$ \\
\hline Payload (kgf) & 4 \\
\hline Operation Speed (cm/sec) & $0.3 \sim 8$ \\
\hline
\end{tabular}

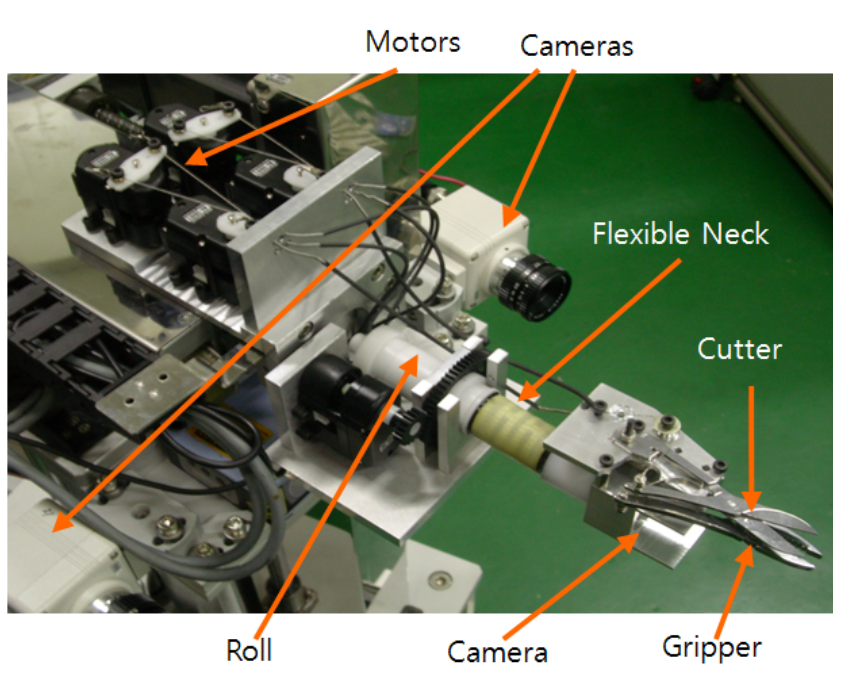

Figure 8. Endoscope type end effector.

Table 4. Specification of end effector

\begin{tabular}{|c|c|}
\hline Item & Measurement \\
\hline $\begin{array}{l}\text { Dimension } \\
\text { (width } \times \text { length } \times \text { height }: \mathrm{cm} \text { ) }\end{array}$ & $13 \times 6 \times 5$ \\
\hline Level of freedom & 2 \\
\hline Function & $\begin{array}{l}\text { Right and left } 30 \text { degrees rotating, } \\
\text { Up and down } 42 \text { degrees bending, } \\
\text { Right and left } 28 \text { degrees bending }\end{array}$ \\
\hline Cutting range & Stem diameter less than $2 \sim 7 \mathrm{~mm}$ \\
\hline Cutting capacity & Stem diameter less than $7 \mathrm{~mm}$ \\
\hline CCD miniature camera & $\begin{array}{l}\text { Image angle } 60 \text { degrees, } \\
\text { focusing distance } 30 \sim 50 \mathrm{~mm}\end{array}$ \\
\hline Used motor & Al motor, torque $10 \mathrm{~kg} \cdot \mathrm{cm}$ \\
\hline
\end{tabular}

robot end effector was developed as shown in Figure 8 and was composed of an imaging unit, stem gripper, and stem cutter so that it was possible to cut a stem off even if it was bent. Specifications for the end effector are presented in Table 4.

For the image processing system, two color cameras and a laser range finder were installed at the fore-end of robot as shown in Figure 9. Table 5 shows the specification

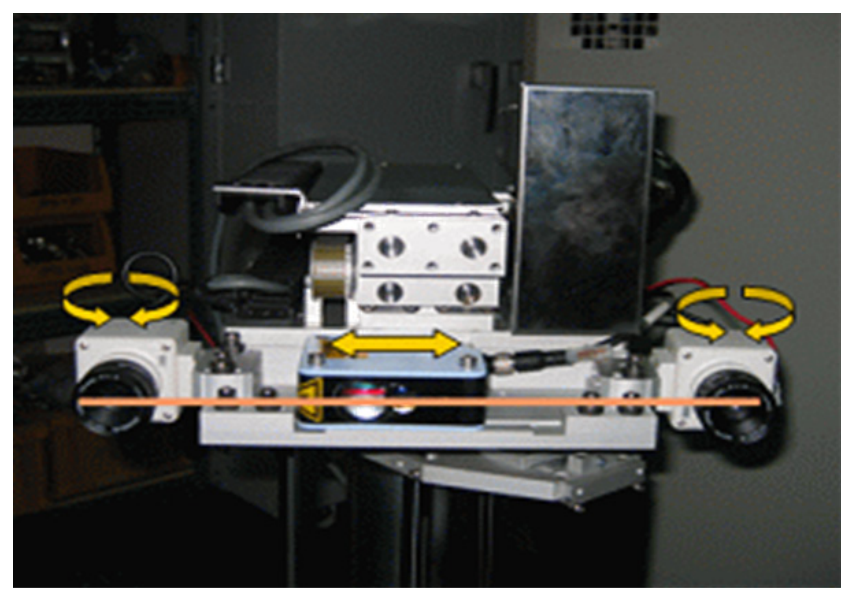

Figure 9. Image acquisition unit and laser range finder.

Table 5. Specification of image acquisition unit and laser range finder

\begin{tabular}{|c|c|}
\hline & Measurement \\
\hline Frame grabber & Matrox CD, Morphis \\
\hline Camera & STC-620, Sensor Technologies America, inc \\
\hline Lens & Vari-focal lens(0.1 ) \\
\hline $\begin{array}{c}\text { Distance } \\
\text { Measurement }\end{array}$ & $\begin{array}{c}\text { S80L-Y, } \\
\text { DATASENSOR 100 1800 mm, } \\
\text { level of detail } 0.9 \mathrm{~mm}\end{array}$ \\
\hline Other functions & $\begin{array}{c}\text { Automatic illumination balance, } \\
\text { automatic color balance }\end{array}$ \\
\hline
\end{tabular}

for the camera and laser range finder.

As a result of measuring the repetitive level of detail for each axis, it was determined that the repetitive error made by the robot has very little influence on its harvesting capability (target error were $\pm 0.7 \mathrm{~mm}$ ), as shown in Figure 10 and Table 6.

Figure 11 shows the process for extracting strawberries from the background in color image. Since a ripened strawberry has relatively high chromaticity compared to the background and has a red spectrum, these two properties are used as extraction criteria (see Figure 11 (b) and (c)). The ripened strawberries can be completely segmented by logical multiplication between the thresholded chromaticity and color saturation images as shown in Figure 11 (f).

By labeling the segmented regions the desired strawberry is selected and the position information for servoing via visual feedback is obtained from the centroid of the selected segmented region.

Figure 12 shows resulting images at each step of the image processing stage for the strawberry stems. First, 

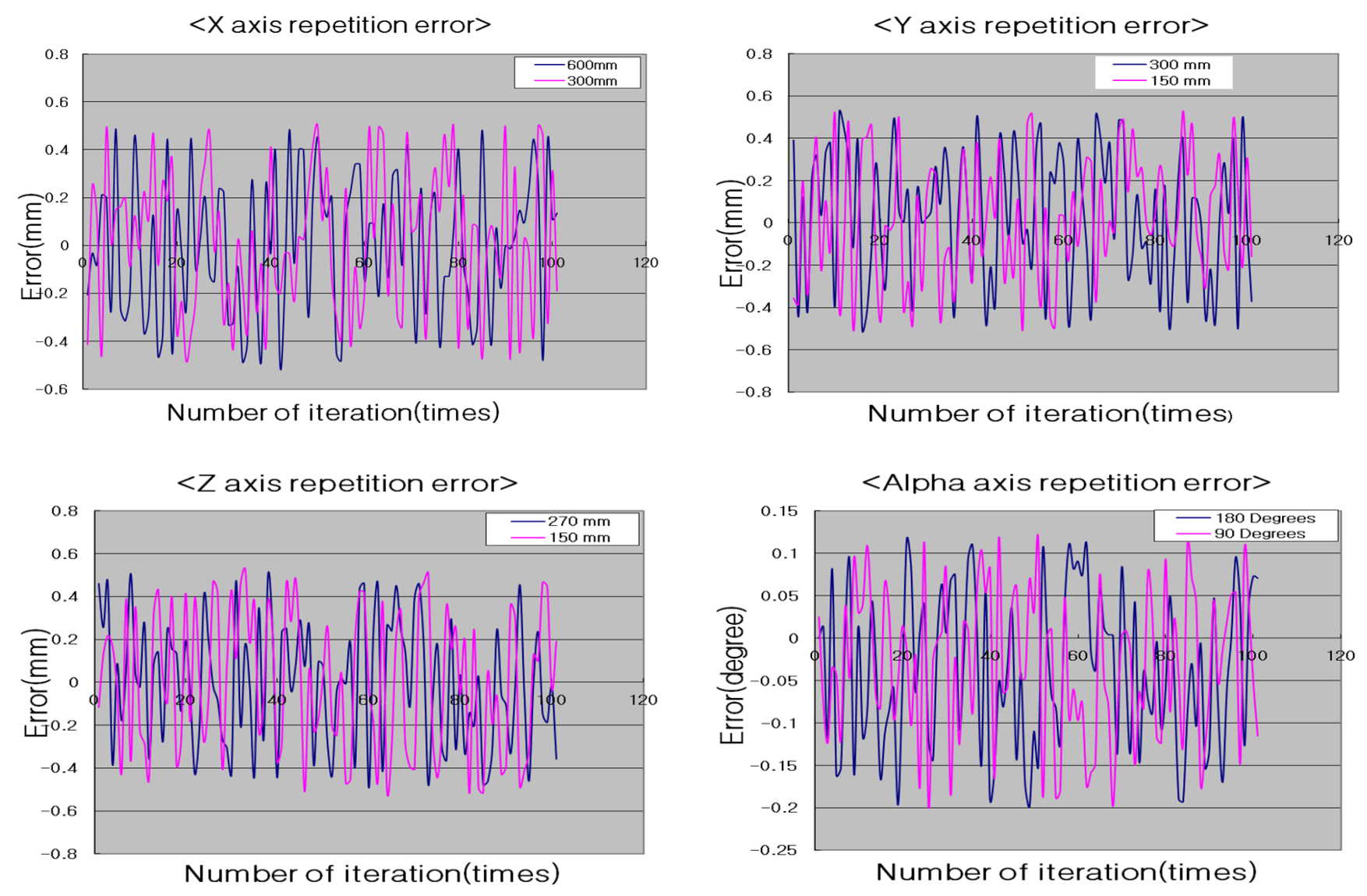

Figure 10. Repeatability errors of each axis.

Table 6. Repeatability errors of each axis

\begin{tabular}{|c|c|c|c|c|c|c|c|c|}
\hline \multirow{2}{*}{$\begin{array}{l}\text { Test speed } \\
(\mathrm{mm} / \mathrm{sec})\end{array}$} & \multicolumn{2}{|c|}{$x$ axis } & \multicolumn{2}{|c|}{$y$ axis } & \multicolumn{2}{|c|}{$z$ axis } & \multicolumn{2}{|c|}{ Alpha axis } \\
\hline & $\begin{array}{c}\text { average error } \\
(\mathrm{mm})\end{array}$ & $\begin{array}{l}\text { Standard } \\
\text { Deviation }\end{array}$ & $\begin{array}{c}\text { average error } \\
(\mathrm{mm})\end{array}$ & $\begin{array}{l}\text { Standard } \\
\text { Deviation }\end{array}$ & $\begin{array}{c}\text { average error } \\
(\mathrm{mm})\end{array}$ & $\begin{array}{l}\text { Standard } \\
\text { Deviation }\end{array}$ & $\begin{array}{l}\text { average error } \\
(\mathrm{mm})\end{array}$ & $\begin{array}{l}\text { Standard } \\
\text { Deviation }\end{array}$ \\
\hline 90 & & & & & & & -0.031 & 0.00401 \\
\hline 150 & & & 0.023 & 0.1398 & 0.01 & 0.1435 & & \\
\hline 180 & & & & & & & -0.037 & 0.00398 \\
\hline 270 & & & & & 0.001 & 0.1415 & & \\
\hline 300 & 0.013 & 0.1407 & 0.038 & 0.1299 & & & & \\
\hline 600 & 0.002 & 0.1213 & & & & & & \\
\hline
\end{tabular}

the chromaticity, color saturation, and lightness images (Figure 12 (b), (c), and (d)) are calculated from the original image Figure 12 (a). After noises are removed from the each image (Figure $12(\mathrm{e}),(\mathrm{f})$, and (g)), the line components of the stem are extracted by logical multiplication (Figure $12(\mathrm{~h}),(\mathrm{i}),(\mathrm{j})$, and (k)) and boundary detection (Figure 12 (1)). The closest line component to the centroid of the segmented region is identified as the real stem of the strawberry.

In the case of strawberries, the average location errors from image processing were $0.24 \mathrm{~mm}$ for $\mathrm{X}$ axis, 0.239 $\mathrm{mm}$ for $\mathrm{Y}$ axis. In the case of stems, the average location errors were $0.34 \mathrm{~mm}$ for $\mathrm{X}$ axis. The average processing time was of 0.3 seconds.

Figure 13 shows that the result of the image processing was almost constant with respect to time. As result of experiment via natural right. From this, precise extraction of strawberry location information was possible regardless of lighting variability.

The average number of repetitions of position detection 


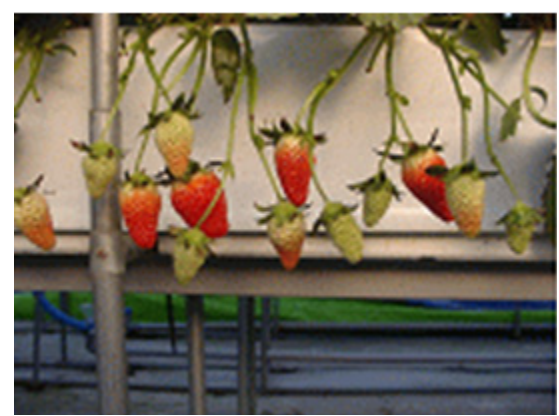

(a)

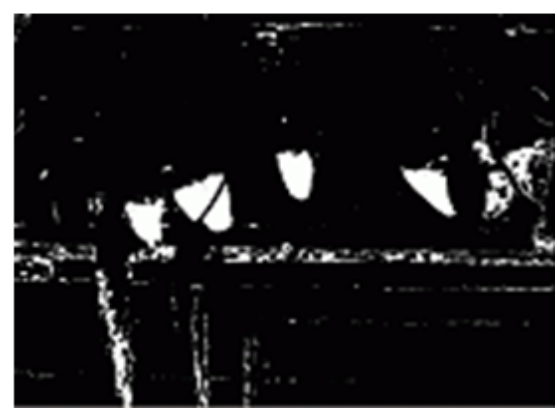

(d)

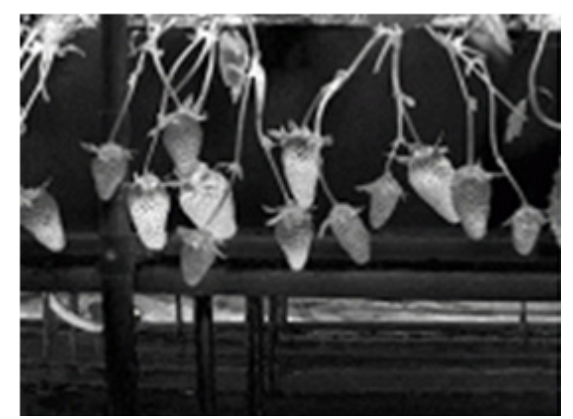

(b)

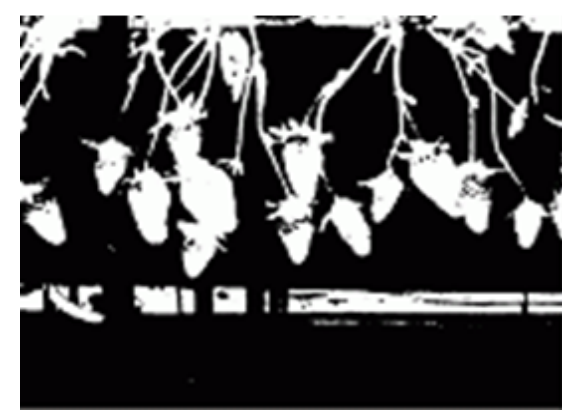

(e)

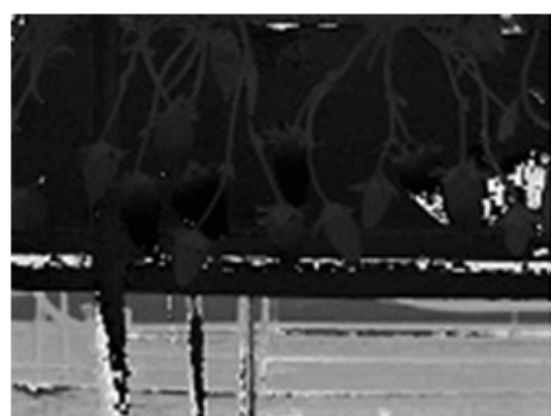

(c)

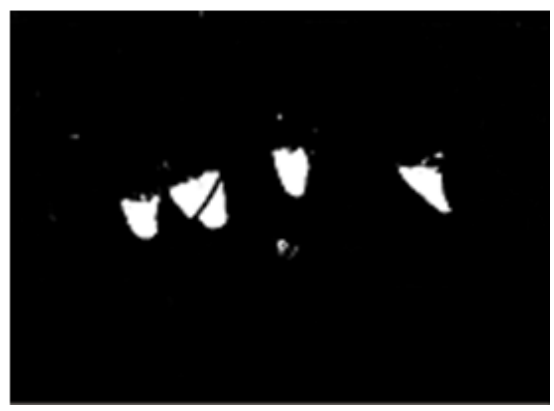

(f)

Figure 11. Results after image processing in the case of strawberries.

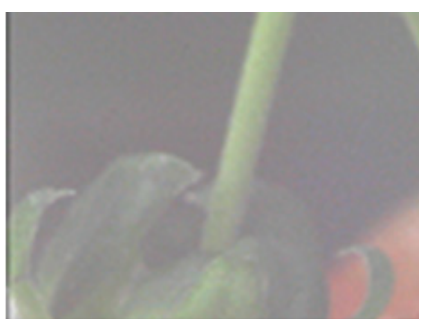

(a)

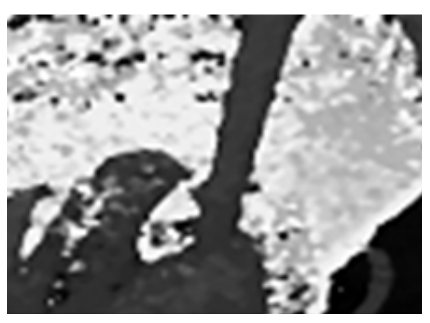

(e)

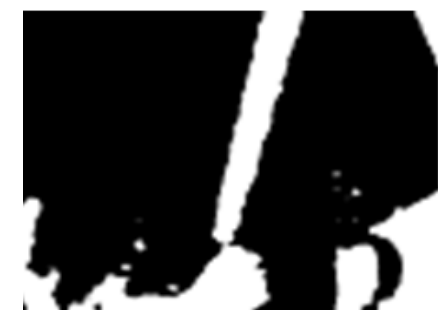

(i)

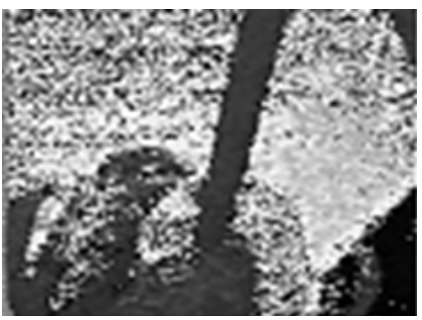

(b)

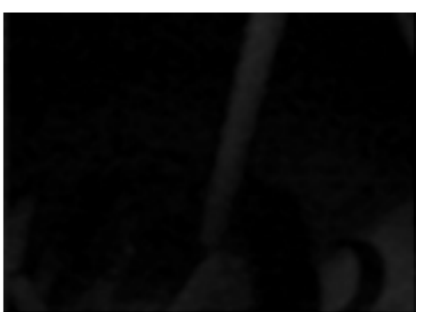

(f)

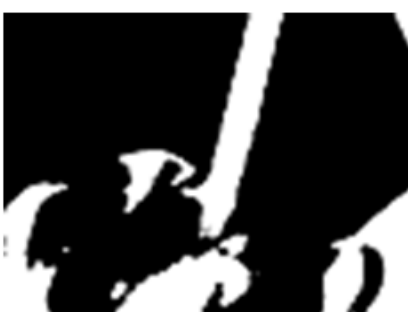

(j)

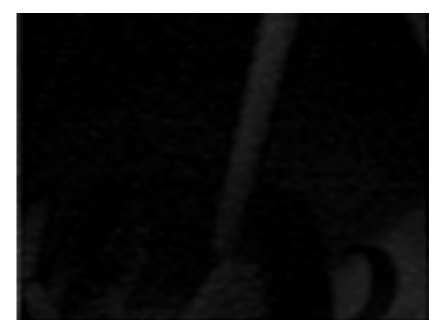

(c)

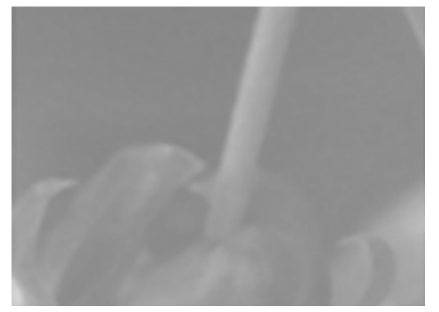

(g)

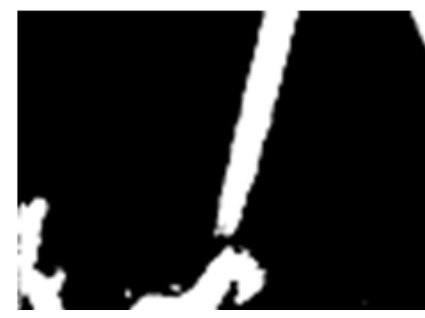

(k)

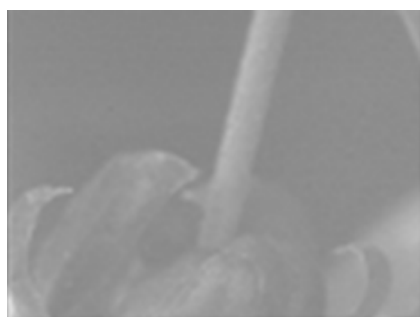

(d)

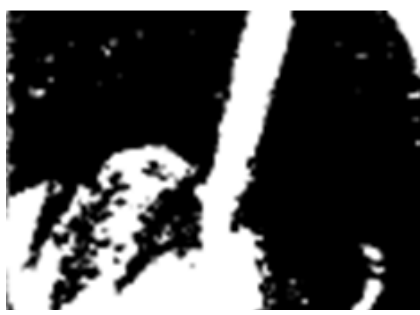

(h)

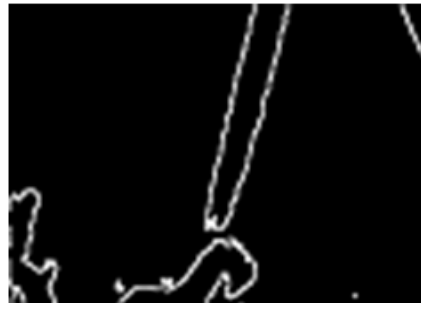

(I)

Figure 12. Results after image processing in the case of stems. 


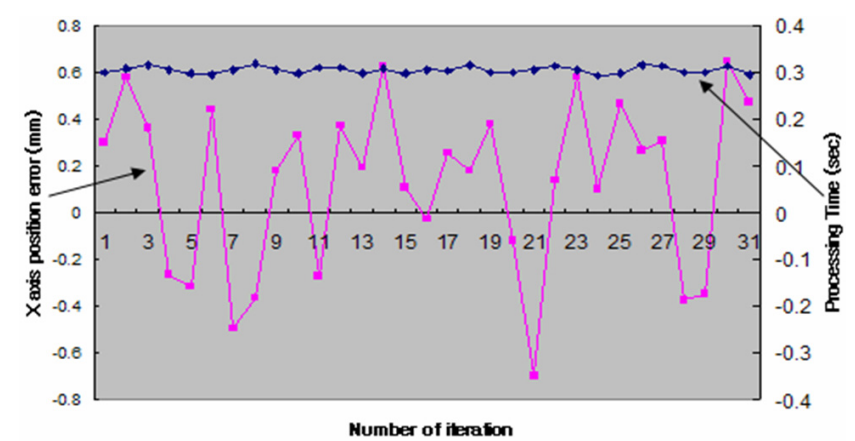

Figure 13. Stem location recognition.
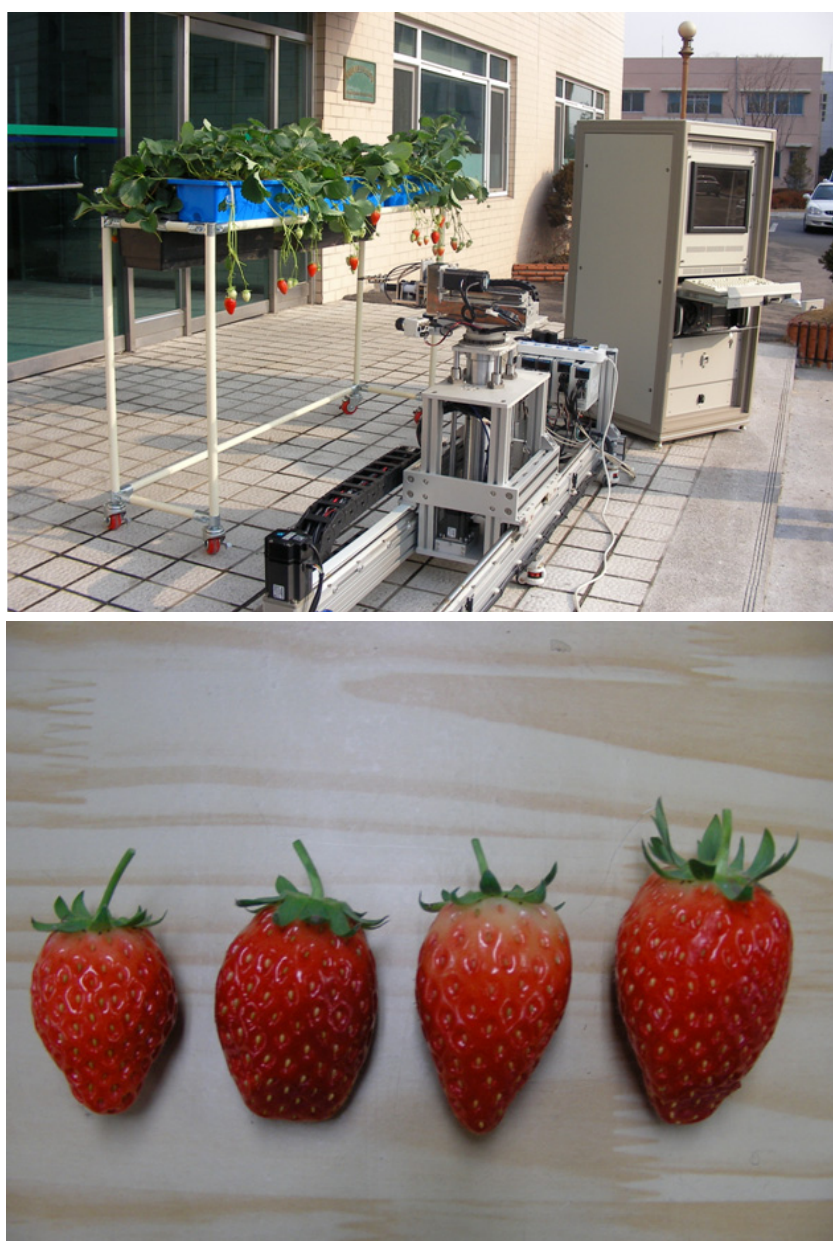

Figure 14. A strawberry harvesting robot and harvested strawberries.

was 1.25 times. It was thought that position trace would be operated very quickly, but this result was acquired in a laboratory setting. Figure14 shows the developed robotic system and harvested strawberries. The system software was developed as shown in Figure15.

We could harvest one strawberry in an average time of 7 seconds as a result of continuous harvesting under the condition of random strawberry location, lighting, natural right, wind, and shadow with under 0.1 seconds for

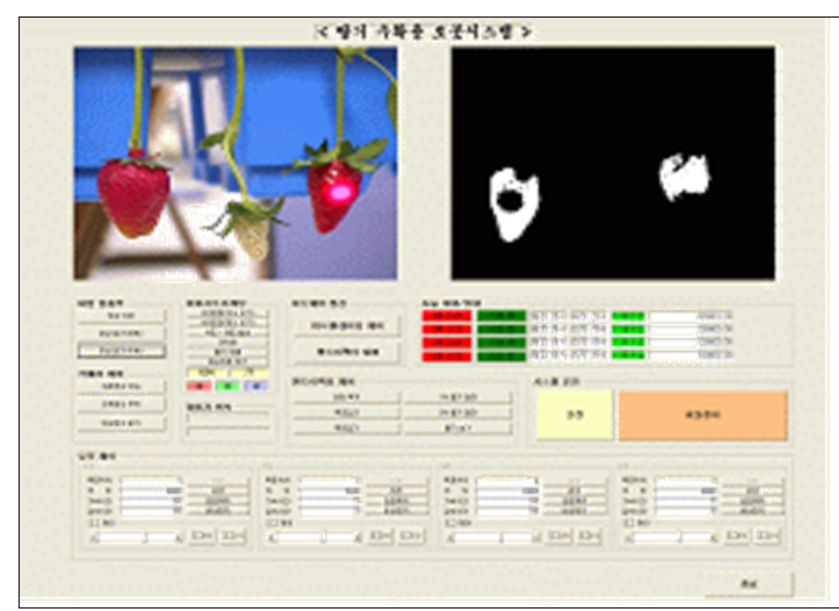

Figure 15. Integrated system control module.

cutting time. However, when the leaves were completely covered or wind was too severe, harvesting becomes difficult or took a longer time.

\section{Conclusions}

A Cartesian type robot manipulator was developed and the authors showed the simplicity of the system as well as ease in control and approach to the strawberry stem perpendicularly. A rotating axis was added to use both sides of the cultivation passageway. Particularly, the largest workplace could also be used in a smaller place by designing the $\mathrm{Z}$ axis of the robot arm to be double-induced because it was hard to have enough working space. The strawberry harvest robot system could successfully adapt to a complex lighting condition by integrative application of a stereo color CCD camera and a laser range finder.

A visual feedback scheme was introduced to precisely trace the strawberry. The stem trace was done initially by driving an end effector roughly based on 2-dimensional information. An additional color camera was used for the precise real time tracking. Strawberries were extracted under variable light conditions and processing speed was around 0.03 seconds.

To improve the system working speed, a multi-functional end-effector was developed such as a servo-controlled gripper and servo-controlled scissors with a vision unit. The imaging unit was easily aligned with a laser range finder. The maximum robot speed was $1,000 \mathrm{~mm} / \mathrm{s}$ and was controlled to around $250 \mathrm{~mm} / \mathrm{s}$ to prevent damage via rotational inertia. The harvesting time for one unit was around 7 seconds. 


\section{Conflict of Interest}

No potential conflict of interest relevant to this article was reported.

\section{Acknowledgments}

This study was supported by 2006 Post-doctoral Fellowship Program (Project No.PJ004370) of National Academy of Agricultural Science, Rural Development Administration, Republic of Korea.

\section{References}

Arima, S. and N. Kondo et al. 1994. Study on cucumber harvesting robot. Journal of the Japanese Society of Agricultural Machinery 56(6):69-76.

C. H. Lee and H. Hwang, 1996. Development of robust feature recognition and extraction algorithm for dried oak mushrooms. Journal of the Korean Society for Agricultural Machinery 21(3):325-335 (In Korean, with English abstract).

Gonzalez R.C. and Woods R.E. 1992. Digital image processing. Boston, MA: Addison-Wesley Pub. Co.
Guo Feng, Cao Qixin and Nagata Masateru. 2008. Fruit detachment and classification method for strawberry harvesting robot. International Journal of Advanced Robotic Systems 5(1):41-48.

H. Hwang, S. C. Kim, D. Y. Choi. 2003. Development of multi-functional tele-operative modular robotic system for watermelon cultivation in greenhouse. Journal of the Korean Society for Agricultural Machinery. 28(6): 517-524 (In Korean, with English abstract).

Kondo N. 2000. Strawberry harvesting robot. Journal of the Japan Society of Mechanical Engineers 103(976): 148-149.

Kondo N., Nishitsuji P., P.Ling and K. C. Ting. 1996. Visual feedback guided robotic cherry tomato harvesting. Transactions of the ASAE 39:2331-2338.

Lieten F. and W. Baets. 1990. Annual report strawberries. proefbedrijf der Noorderkempen. Meerle: 160.

Nagata M., Gejima Y., Shrestha B.P., Hiyoshi K. and Ootsu K. 2000. Basic study on strawberry harvesting robot: Part I . Proceeding of the bio-robotics II: 51-58.

Umeda, M., M. Iida and S. Kubota. 1997. Development of watermelon harvesting robot stork. Bio-Robotics 97:137-142

Van Looy. J and J. Aerts. 1982. Annual report strawberries. proefbedrijf der Noorderkempen. Meerle : 146. 